\title{
New opportunity for serotonin receptor agonists
}

With type 2 diabetes prevalence increasing at an alarming rate, there is a growing need for novel treatments. Recent work suggests that central neural pathways may have an important role in glucose homeostasis, with such pathways having the potential to be therapeutically modulated. Now, writing in Cell Metabolism, Heisler and colleagues show that serotonin $2 \mathrm{C}$ receptor agonists can improve glucose tolerance and reduce plasma insulin levels. This suggests that pharmacological modulation of serotonin receptor activity may be an effective new approach to treat type 2 diabetes.

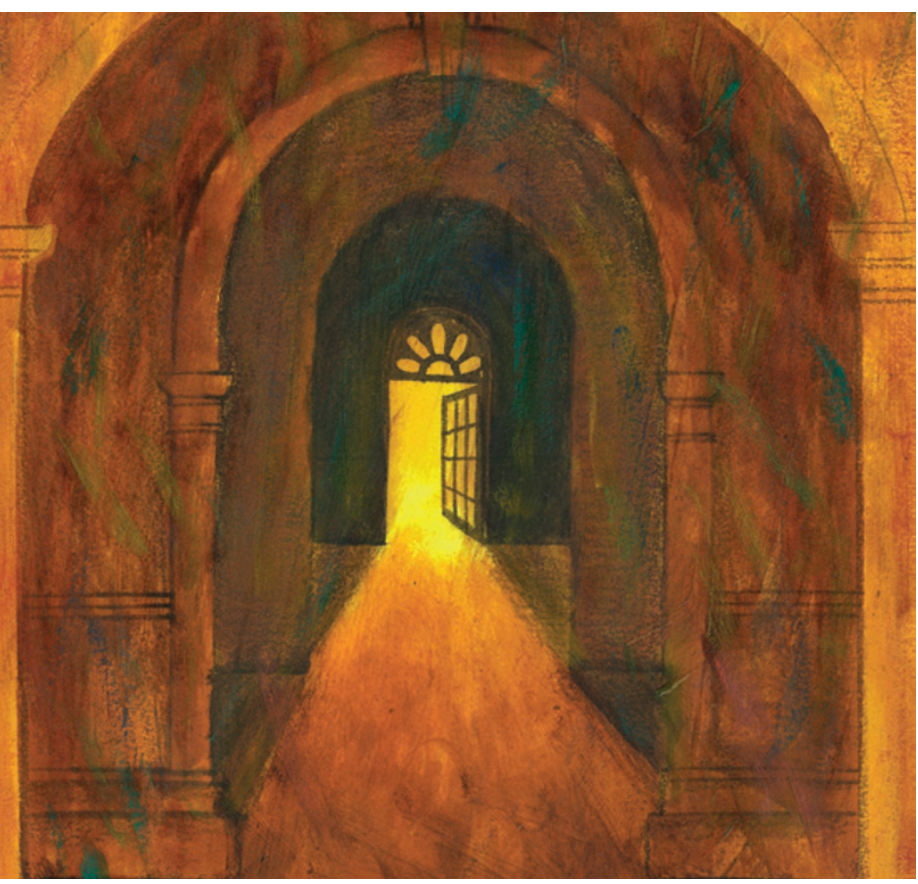

Serotonin (5-hydroxytryptamine; 5-HT) plays important roles as a neurotransmitter in the CNS and as a mediator of peripheral signals. It acts on members of the seven 5-HT receptor families to exert various actions, including the regulation of anxiety, body temperature, mood, sleep and appetite. Pharmacological modulators of specific 5-HT receptor isoforms have been developed to treat various conditions that are associated with these actions, including exploitation of the anorectic effect following central $5-\mathrm{HT}_{2 \mathrm{C}}$ receptor activation for the treatment of obesity. In mice, deletion of $5-\mathrm{HT}_{2 \mathrm{C}}$ receptors leads to insulin resistance and type 2 diabetes, but the possibility of receptor activation for treatment of this disease is largely unexplored.

Therefore, to determine whether $5-\mathrm{HT}_{2 \mathrm{C}}$ receptor stimulation could have beneficial effects on glucose homeostasis, the authors treated insulin-resistant mouse models with specific $5-\mathrm{HT}_{2 \mathrm{C}}$ receptor agonists. Diet-induced obese mice and leptindeficient Lep ${ }^{\mathrm{ob}}(o b / o b)$ mice treated for 2 weeks with $5-\mathrm{HT}_{2 \mathrm{C}}$ receptor agonists, such as $\mathrm{m}$-chlorophenylpiperazine, exhibited a dramatic $50 \%$ reduction in plasma insulin levels in both models. Importantly, this was without effects on blood glucose, food intake, activity or body mass at the doses used in the study. Pharmacological blockade of 5- $\mathrm{HT}_{2 \mathrm{C}}$ receptors abolished effects on glucose tolerance, verifying that these effects were directly mediated by 5- $\mathrm{HT}_{2 \mathrm{C}}$ receptors.
Next, the authors set out to investigate the mechanism of action of these agents and observed that $5-\mathrm{HT}_{2 \mathrm{C}}$ receptor activation stimulated central melanocortin pathways, an action known to enhance insulin sensitivity. In $o b / o b$ mice, 1 week of $5-\mathrm{HT}_{2 \mathrm{C}}$ receptor agonist treatment increased levels of pro-opiomelanocortin - the precursor of the endogenous melanocortin agonist, $\alpha$-melanocytestimulating hormone $(\alpha-\mathrm{MSH})-$ in the arcuate nucleus of the hypothalamus. Pharmacological melanocortin receptor (MCR) blockade and MCRknockout mouse models revealed the subsequent increased level of $\alpha$-MSH improves glucose clearance by stimulating melanocortin 4 receptors (MC4R); enhancing activity of sympathetic preganglionic neurons in the intermediolateral nucleus of the spinal cord. These MC4R-dependent effects occurred in association with decreased plasma insulin levels, improved glucose tolerance, and increased insulin signalling in the muscle and liver.

The identification of improvements in glucose homeostasis following 5- $\mathrm{HT}_{2 \mathrm{C}}$ receptor activation illustrates a new mechanistic strategy to treat type 2 diabetes, highlighting a novel therapeutic application for a class of compounds developed years ago.

\section{Sarah Crunkhorn}

ORIGINAL RESEARCH PAPER Zhou, L. et al. Serotonin $2 \mathrm{C}$ receptor agonists improve type 2 diabetes via melanocortin-4 receptor signaling pathways. Cell Metab. 6, 398-405 (2007) 